\title{
OS IMPACTOS JURÍDICOS FRENTE AO ADVENTO DO BITCOIN ${ }^{1}$
}

THE LEGAL IMPACTS FACING THE ADVENT OF BITCOIN

Arthur Henrique dos Reis MATHEUS ${ }^{2}$

ISSUE DOI: $10.21207 / 2675-0104.2019 .879$

\begin{abstract}
RESUMO
O presente projeto visa principalmente o destaque dos impactos pelas inovações tecnológicas no campo jurídico influenciado pelo advento da criptomoeda (principalmente a Bitcoin). Para tanto, a pesquisa debruça sobre a análise da regulamentação existente no arcabouço jurídico nacional, a permissividade constitucional da atuação (iminente e existente) das criptomoedas na economia brasileira e, por fim, promove a discussão de quais caminhos a sociedade mundial deve se guiar em decorrência deste ativo financeiro que já impacta o mercado global.
\end{abstract}

Palavras-chave: Bitcoin. Criptomoeda. Moeda digital. Impactos socioeconômicos.

\section{ABSTRACT}

This project aims mainly at highlighting the impacts of technological innovations in the legal field influenced by the advent of cryptocurrency (mainly Bitcoin). To this end, the research focuses on the analysis of the existing regulation in the national legal framework, the constitutional permissiveness of the (imminent and existing) performance of cryptocurrencies in the Brazilian economy and, finally, promotes the discussion of which paths the world society should be guided in. result of this financial asset that already impacts the global market.

Keywords: Bitcoin. Cryptocurrencies. Digital currency. Socioeconomics impacts.

\footnotetext{
${ }^{1} \mathrm{O}$ presente artigo sintetiza a monografia de conclusão da pesquisa, realizada para o Programa Interno de Bolsas de Iniciação Científica (PIBIC 2018-2019) da Faculdade de Direito de Franca (FDF), Franca/SP.

${ }^{2}$ Discente da Faculdade de Direito de Franca (FDF), Franca/SP. Bolsista do Programa Interno de Bolsas de Iniciação Científica (PIBIC 2018-2019).
} 


\section{INTRODUÇÃO}

A presente pesquisa trata do advento das criptomoedas, em especial a Bitcoin, sua influência e relevância no mercado global, e os impactos que esta causa dentro do cenário econômico mundial e nacional, bem como os nortes que a sociedade pode tomar para solucionar os impasses nos campos em que as moedas digitais atuam. Para tanto, o primeiro capítulo se incumbirá da análise histórica da moeda e da sociedade a respeito das práticas mercantis até o surgimento dos criptoativos, inseridas no panorama econômico nacional.

Determinado o contexto histórico-social e econômico do surgimento das criptomoedas, cabe, agora, o início da discussão a respeito das lacunas apresentadas pela legislação brasileira atual, sendo que este cenário é o foco da pesquisa, estudando o comportamento da carta maior sobre o tema, debruçando-se, principalmente, na Constituição Econômica (Título VII da CF, artigos 170 e seguintes) com as discussões sobre a permissividade da inserção das moedas digitais perante os princípios elencados no artigo 170, o sistema financeiro nacional, a regulamentação monetária existente e o domínio econômico.

Após as tratativas econômicas (de suma importância para a compreensão do panorama internacional que reflete sobre o Brasil), o capítulo terceiro será o responsável por tratar de toda a estrutura da bitcoin (o exemplo principal dentre as outras moedas digitais), o funcionamento da plataforma, a seguridade que esta apresenta e a confiabilidade que passa. Este capítulo, também, prosseguirá com as tratativas econômicas, no qual, através das características das moedas digitais, se traçará um comparativo entre os maiores representativos históricos de dinheiro: o ouro (importante no processo evolutivo monetário) e o papel-moeda usado atualmente.

O segundo momento da análise acerca da inserção das criptomoedas na economia mundial recairá, primeiramente, sobre a discussão de competência: é internacional ou estatal o dever de regulamentar estes criptoativos? Feito isso, o levantamento dos impactos jurídicos já causados e os possíveis para o futuro que se aproxima é necessário para desenvolver as medidas que já foram tomadas, destacando o que o Brasil já promoveu (ou busca aplicar), mas, principalmente, a aplicação de regulamentação internacional.

Em suma, a pesquisa fomenta a discussão entre um ativo financeiro que anualmente recebe olhares e investimentos diante das barreiras impostas, pela estrutura e funcionamento das próprias moedas 
digitais, ou do posicionamento temerário de uma parcela da população que ainda considera um risco investir seu dinheiro para adentrar na plataforma. O fato é que a influência das criptomoedas no mercado mundial é realidade e a discussão sobre o tema é mais que necessária pela relevância econômica, jurídica e social ${ }^{3}$.

\section{CONSIDERAÇÕES INICIAIS}

Primeiramente, há que se questionar os motivos pelos quais a sociedade historicamente demandou a moeda. É fato que a evolução social tem, em segundo plano, a criação e aprimoramento do dinheiro usado a cada momento histórico analisado. O escambo é o marco inicial, no qual produtos se tornaram moeda de troca, respeitando a necessidade a qual cada indivíduo apresentava de acordo com sua oferta ${ }^{4}$. Desde já é importante que a padronização de algo comum a todos sempre foi a busca, pois houve as moedas-mercadoria e, posteriormente, os metais que, pelas propriedades físicas, durabilidade e alta demanda no mercado se tornaram meios de troca padrão, servindo até como unidade de medida para quantificar outros produtos de baixa procura/oferta.

A era do metalismo é de suma importância para a evolução da moeda pois foi através dela que se iniciou a produção das moedas físicas. Os processos de fundição, purificação, refinação e cunhagem da barra e da moeda, bem como a não perecibilidade do ouro, prata e bronze foram primordiais para o início da padronização de valores, os quais recaiam inteiramente sobre as moedas produzidas, primeiramente com valor intrínseco (comercial) e, posteriormente, extrínseco (gravado no metal). ${ }^{5}$

É importante a análise do advento da moeda pois, através do metalismo, que se introduziu o conceito de lastro, além de que se vê claramente a otimização das transações, permeadas pela padronização que promovia a celeridade de compra e venda. Com isso, a evolução da moeda ganha uma nova etapa, ainda na Idade Média ${ }^{6}$, com a criação da moeda-

\footnotetext{
${ }^{3}$ Bitcoin e o impacto da tecnologia blockchain na economia mundial. [S. 1.], 23 jul. 2018. Disponível em: https://www.hsm.com.br/bitcoin-e-o-impacto-da-tecnologia-blockchain-na-economiamundial/. Acesso em: 19 jul. 2019.

${ }^{4}$ Singer, Paul - 1032. Aprender economia / Paul Singer. $21^{\circ}$ ed.- São Paulo. Rossetti, José Paschoal, Introdução à economia / São Paulo: Atlas, 1994.

${ }^{5}$ BANCO CENTRAL DO BRASIL. Origem e evolução do dinheiro. [S. 1.], [20--?]. Disponível em: https://www.bcb.gov.br/htms/origevol.asp. Acesso em: 18 jul. 2019.

${ }^{6}$ Ibid.
} 
papel, um documento representativo de depósito (em ouro e/ou prata) lastreada por um ourives (garantidor). Além de potencializar as transações, a praticidade se tornou um atrativo para a ascensão da moeda papel, bem como a segurança, tendo em vista que o comercio ainda era promovido sobre longas distâncias por caravanas que poderiam sofrer ataques de assaltantes e que, se estivessem sob a detenção de metais preciosos seriam saqueados.

Após a expansão dos mercados e do enrijecimento da economia pelo mercantilismo, além da histórica ascensão robusta dos Estados que, ao chegar no mundo moderno, surge o papel-moeda ${ }^{7}$. Com ele há a ruptura do lastro, sendo que a confiabilidade conferida pela entidade estatal, com curso forçado e reserva de valor, uma postura intervencionista para assegurar o poderio governamental sobre os interesses econômicos. Paralelo à regulação monetária estatal, o final do século $\mathrm{XX}$ e início do seguinte promovia alterações substanciais à sociedade, com a globalização, promovendo a aproximação socioeconômica dos Estados através das inovações tecnológicas que conceberam, além dos produtos, um ambiente virtualizado (a World Wide Web), bem como o fomento à indústria bélica que resulta na criação da internet, pilar fundamental para o surgimento do mundo globalizado. É no mundo moderno, também, que as entidades bancárias percebem que, com o universo digital em expansão, as forças computacionais e a evolução exponencial da tecnologia, poderiam trabalhar com a desnecessidade do dinheiro físico, mas que a confiabilidade que o banco ofereceria seria suficiente para desmaterializar a moeda e conferir a existência em um plano virtual, surgindo, assim, o crédito.

Já a segunda década do século XXI apresenta mais inovações e avanços que permearam uma nova etapa da evolução histórica da moeda. A globalização é um processo a qual é impossível desassociar, tendo em vista que o intercâmbio sociocultural e econômico é algo solidificado na atualidade, a qual permite transcender barreiras geográficas e políticas, promove o crescimento do fluxo internacional de bens, serviços e capitais e o aumento da interdependência dos agentes e sistemas econômicos nacionais, reflexos do mundo globalizado, segundo indica Reinaldo Gonçalves ${ }^{8}$. Além disso, a tecnologia cresceu exponencialmente,

\footnotetext{
7 SILVA, Vinicius Carlos da. História da moeda. [S. 1.], [20--?]. Disponível em: https://www.portalsaofrancisco.com.br/historia-geral/historia-da-moeda. Acesso em: 15 jan. 2019.

8 GONÇALVES, Reinaldo. Globalização econômica. Disponível em: http://www.ie.ufrj.br/intranet/ie/userintranet/hpp/arquivos/texto_no._1_globalizacao_economica.pdf. Acesso em: 10 dez. 2018.
} 
alcançando a otimização de produtos e serviços apresentados em tamanho avanço que fomentou a quarta revolução industrial (ou indústria 4.0), a qual conceitos de nano e biotecnologia, robotização, inteligência artificial e armazenamento de dados em nuvens alguns dos conceitos que não somente são pilares, como efetivamente já são realidade no panorama industrial e econômico.

Logo, através de um novo sistema financeiro internacional e da expansão do ciberespaço, consequências de um mundo globalizado pelos avanços tecnológicos, é que surgem as criptomoedas. Entretanto, cabe a análise: moedas digitais são, de fato, demandadas pela sociedade atual? Tatiana Barbosa é categórica ao afirmar que "A evolução da internet, combinada com a insatisfação da população frente aos regimes políticos e instituições financeiras, fizeram com que a cada dia as moedas digitais fossem procuradas por mais usuários, consolidando assim uma nova moeda"9. A demanda é real e já atua no mercado internacional, visto que não somente influencia na economia mundial, como países já se movimentam para regulamentar e se posicionar perante este novo conceito, sendo um número pequeno dos que se prostram negativamente às criptomoedas ${ }^{10}$.

Portanto, visto que as criptomoedas já influem sobre o panorama econômico-social de hoje, faz-se necessário o estudo da permissividade destas em confronto com a análise constitucional e jurídica brasileira. Para isso, a Constituição Econômica será o foco, uma abordagem para compreensão da realidade nacional perante à inserção das criptomoedas.

\section{CONSTITUIÇÃO ECONÔMICA E A MOEDA DIGITAL}

Através de um retrospecto histórico, vê-se que a criação da Constituição Econômica foi um processo histórico culminado pela crise de

\footnotetext{
${ }^{9}$ BARboSA, Tatiana Casseb B. M. et al. A Revolução das Moedas Digitais: Bitcoins e Altcoins. São Paulo: Revoar, 2016.

${ }^{10}$ ROQUETTE, Luis. Bitcoin e regulamentação pelo mundo: Uma análise completa sobre o futuro da moeda. [S. 1.], 24 dez. 2018. Disponível em: https://www.oinvestidormoderno.com.br/bitcoin-eregulamentacao-uma-analise-completa/. Acesso em: 19 ago. 2019.
} 
1929 e $2^{\mathrm{a}}$ Guerra Mundial ${ }^{11}$ que efetivaria, segundo Vital Moreira destaca $^{12}$, a realização de uma determinada ordem econômica por meio de normas ou instituições jurídicas instituidoras de uma forma de organização e funcionamento da economia.

No Brasil, a Constituição Econômica somente recebeu a devida importância na carta maior de 1988, sendo tratada em um título específico e seguindo o que fora consolidado pelo mundo inteiro. Anterior a isso, desde a Constituição de $1934^{13}$, que iniciou as tratativas econômicas em capítulo apartado até que alcançasse a importância de um capítulo completo, representativa da necessidade de redemocratização do país após o período ditatorial e clamor público pelo retorno dos direitos e garantias fundamentais ${ }^{14}$. Com isso, o título VII (artigos 170 a 192) da Constituição Cidadã ficou responsável por apresentar os nortes da ordem econômica brasileira.

\section{1 $\quad$ NÁLISE LEGISLATIVA DOS PRINCÍPIOS}

Os princípios econômicos são tratados no artigo 170 da Constituição Federal de 1988, sendo fundamentos da atividade econômica. André Ramos Tavares indica que a justiça social, a existência digna e o desenvolvimento nacional são os três maiores objetivos para nortear a economia brasileira ${ }^{15}$, sendo que os princípios concedem a harmonia necessária para alcançar as finalidades que o Estado anseia.

\footnotetext{
Art. 170. A ordem econômica, fundada na valorização do trabalho humano e na livre iniciativa, tem por fim assegurar a todos existência digna, conforme os ditames da justiça social, observados os seguintes princípios:

I - soberania nacional;

II - propriedade privada;
}

11 AGUIAR, B. A. T. A constituição econômica: breve síntese. [S. l.], 2013. Disponível em: https://ambitojuridico.com.br/edicoes/revista-110/a-constituicao-economica-breve-sintese/. Acesso em: 18 jul. 2019.

${ }^{12}$ MOREIRA, Vital. Economia e Constituição, 1979 apud FONSECA, João Bosco Leopoldino. Direito Econômico. $2^{\mathrm{a}}$ Edição, Rio de Janeiro: Editora Forense, 1997.

13 BATISTI, N. E. M. Evolução da ordem econômica no contexto político-econômico das constituições brasileiras. 2007. Dissertação (Mestrado em Direito Negocial) - Universidade Estadual de Londrina, Londrina, 2007.2 Disponível em: http://www.dominiopublico.gov.br/download/teste/arqs/cp044787.pdf. Acesso em: 19 jul.

${ }^{14}$ Ibid.

${ }^{15}$ TAVARES, André Ramos. Direito Constitucional Econômico. São Paulo: Método, 2011. p. 126. 


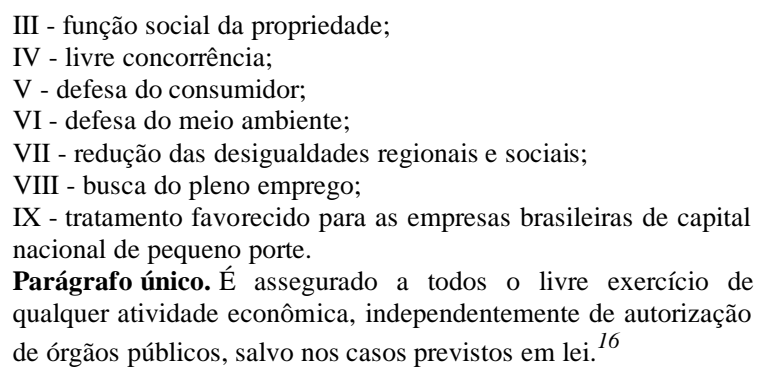

A análise dos princípios permite perceber que as criptomoedas não produzem nenhuma consequência nociva à economia brasileira. Quanto à soberania nacional, esta deve ser tratada com o devido valor pois, uma proposta de moeda em plano virtual que interfere todos os países, independente de sua anuência poderia ser tratada como uma situação negativa às entidades estatais. Friederich Hayek em Desestatização do Dinheiro ${ }^{17}$ propõe, através de teoria, uma proposta extrema a qual o Estado não deveria obter o monopólio de produção da moeda para que a sociedade pudesse ter o livre arbítrio de optar por qual tipo de dinheiro desejasse usar. De fato, é uma tese liberal e danosa à economia global, sendo até utópica pela estrutura histórica, sólida e consolidada da soberania nacional, não por ser uma simples questão tradicionalista, mas que haja a coexistência pacífica entre o Estado soberano com a moeda que este trabalha para que a economia circule em seu território nacional, porém com a permissividade de um meio virtualizado para pagamentos que, através da globalização, o intercâmbio cultural exista de forma mais eficiente, o que será visto, posteriormente, que não altera a estrutura política do país, muito menos prejudica sua soberania.

Outro ponto importante com relação aos princípios é a respeito da propriedade privada: Fernando Ulrich sustenta que, ainda que não sejam aceitas como moeda pela legislação nacional, as criptomoedas são bens econômicos que representam um valor ${ }^{18}$; Logo, é justo que as moedas digitais possam agir como bens sem confrontar o real livremente circulado, é uma garantia do indivíduo e segurança jurídica para que os agentes

\footnotetext{
16 BRASIL. [Constituição (1988)]. CONSTITUIÇÃo DA REPÚBLICA FEDERATIVA DO BRASIL. Organização de Alexandre de Moraes. 16.ed. São Paulo: Atlas, 2000.

${ }^{17}$ HAYEK, Friederich A. Desestatização do dinheiro. São Paulo: Instituto Ludwig von Mises, 2011. p. 166.

${ }^{18}$ ULRICH, Fernando. Bitcoin: a moeda na era digital. São Paulo: Instituto Ludwig Von Mises Brasil, 2014. p. 47.
} 
econômicos possam atuar no mercado (pressuposto de liberdade de iniciativa), conforme destaca Vicente Bagnoli ${ }^{19}$.

Os demais princípios se comportam de forma permissiva à atuação das criptomoedas no mercado nacional e harmonizam os interesses do Estado na economia e os insurgentes anseios da população pela influência do ciberespaço, produtos e serviços oferecidos por este.

\subsection{O SISTEMA FINANCEIRO E A REGULAMENTAÇÃO MONETÁRIA}

O artigo 192 da Constituição Federal é a consolidação de um longo processo de mutação e históricas intervenções. Desde o Brasil colônia há registros de um protótipo sistemático com a utilização das moedas-mercadorias e os metais preciosos na função de dinheiro ${ }^{20}$, enquanto o período regencial já demonstrava a necessidade de um banco com funções centrais e comerciais ${ }^{21}$, sendo que o órgão criado apenas tinha a emissão da moeda como obrigação para manter os interesses monárquicos.

O primeiro Banco do Brasil surgiu em 1905, o qual conferiu ao Estado o maior controle econômico e normativo, sendo que, 15 anos depois, surgiria a Inspetoria Geral dos Bancos (órgão fiscalizador) ${ }^{22}$. Entretanto, o país demonstrava carência de um órgão que controlasse a oferta da moeda - estava a cargo do Banco do Brasil - o que somente foi suprido em 1945 com a Superintendência da Moeda e do Crédito $(\text { SUMOC })^{23}$, capaz de controlar o mercado financeiro, combater a inflação e preparar o país para a criação de um banco central. A preparação durou 19 anos e em 1964 foi criado o Banco Central do Brasil, autarquia federal do Sistema Financeiro Nacional, que recebeu a competência para emitir moeda-papel, executar serviços do meio circulante entre outras funções que os artigos 10 e 11 da Lei $n^{\circ} 4.595 / 64$ conferiu ao órgão ${ }^{24}$.

\footnotetext{
${ }^{19}$ BAGNOLI, Vicente. Direito econômico. São Paulo: Atlas, 2008. p. 65.

${ }^{20}$ VIEIRA, J. A. G.; PEREIRA, H. F. S.; PEREIRA, W. N. A. Histórico do Sistema Financeiro Nacional. E-locução - Revista científica da FAEX, Extrema - MG, 2012. Disponível em: https://faex.edu.br/_arquivos/_revistas/322125001348776758_10.pdf. Acesso em: 19 jul. 2019. p. 147. ${ }_{21}$ BANCO CENTRAL DO BRASIL. História do BC. [S. 1.], [20--?]. Disponível em: https://www.bcb.gov.br/pre/historia/historiabc/historia_bc.asp?frame=1. Acesso em: 19 jul. 2019.

22 Ibidem

${ }^{23}$ Ibid.

${ }^{24}$ Ibid.
} 
O reordenamento do sistema financeiro nacional ocorreu entre 1985 e 1988, sendo separado entre dois subsistemas: de supervisão (agregando Conselho Monetário Nacional - CMN -, Banco Central BACEN -, e Comissão de Valores Mobiliários - CVM) e de operação ou operativo (representando as instituições financeiras bancárias e não bancárias, agentes especiais, sistema de pagamentos e de distribuição e TVM - Teorema de valor médio - e o SBPE - Sistema Brasileiro de Poupança e Empréstimo $)^{25}$. Este é um marco para a economia brasileira pois conferiu uma estrutura sólida capaz de movimentar o capital de forma otimizada. Embora as criptomoedas não possam ser tratadas como moedas, mas sua concepção se sustenta em pilares da economia atual: o crédito e a moeda escritural, frutos da evolução dos sistemas financeiros e, para o Brasil, da solidificação e robustez que o SFN atual criou.

\subsection{INTERVENÇÃO DO ESTADO NO DOMÍNIO ECONÔMICO: FISCALIZAÇÃO, INCENTIVO E PLANEJAMENTO QUANTO ÀS CRIPTOMOEDAS}

Há que se destacar, ainda na Constituição Econômica Brasileira, a importância dos artigos 173 e 174: o primeiro indica que a exploração da economia fica a cargo do agente privado e, ao Estado, sua atuação será como garantidor da segurança nacional e interesse coletivo; o artigo seguinte traça como objetivos da União, Estados membros, Distrito Federal e Municípios a fiscalização, incentivo e planejamento.

Com isso, os agentes econômicos de natureza privada e o Estado atuando como estes ("agente normativo e regulador da atividade econômica" ${ }^{26}$, conforme artigo 174 da $\mathrm{CF} / 88$ ) agem com o resguardo da carta maior, concorrendo igualitariamente. Assim, após traçar o percurso histórico das moedas e econômico, faz-se necessário adentrar ao tema para compreensão do funcionamento, a plataforma das criptomoedas e os impactos econômicos e jurídicos que estas provocam na atualidade.

\footnotetext{
${ }^{25}$ BANCO CENTRAL DO BRASIL. Como funciona o sistema financeiro nacional. [S. 1.], abr. 2008. Disponível em: https://www.bcb.gov.br/Pre/bcUniversidade/Palestras/Sistema\%20Financeiro\%20Nacional.pdf. Acesso em: 19 jul. 2019.

${ }^{26}$ BAGNOLI, Vicente. Direito econômico. São Paulo: Atlas, 2008. p. 73.
} 


\section{BITCOIN: CONCEITO, SURGIMENTO E ESTRUTURA POR TRÁS DO SUCESSO}

Em 31 de outubro de 2008 surgiu a bitcoin, um sistema de pagamentos eletrônico instituído por Satoshi Nakamoto (pseudônimo usado pelo usuário $)^{27}$. A proposta era ousada: um conceito de liberdade monetária fundamentada em sua integralidade no ciberespaço, excluindo intermediários financeiros que conferiria sua segurança sistêmica intrinsecamente ligada à plataforma a qual sustentava a criptomoeda em questão.

As transações dentro do sistema envolveriam apenas a bitcoin, sendo esta "moeda" divisível em até oito casas decimais, compiladas em um registro contábil público batizado de blockchain (ou cadeia de blocos), responsável por sustentar as informações relativas aos negócios promovidos na plataforma desde sua concepção até a atualidade, traçando um histórico perfeito de cada moeda digital negociada até a atualidade. Todo o pagamento feito na bitcoin client seria confirmado por um servidor descentralizado, arquitetura conhecida como rede peer-to-peer (ponto-aponto ou $\mathrm{P} 2 \mathrm{P}$ ), no qual o compartilhamento de dados não exige um servidor central que os comporte e valide, uma força computacional distribuída ${ }^{28}$.

Com isso, os pagamentos são validados pelos próprios usuários da rede, conhecidos como mineradores (ou bitcoin miners). A mineração é um processo verificação de transações feita pela própria força computacional baseada na solução de um problema matemática apresentada aos maquinários pelo sistema, recebendo uma prova de trabalho (proof-of-work) em bitcoins aquele que resolver primeiro a complexa equação. Este processo recebe este nome pois o sistema não lançou livremente todas as 21 milhões de unidades de bitcoin, a mineração é que vai aumentando este número. Atualmente, $80 \%$ da quantidade total é que circula no mercado, sendo que a expectativa é que o último bitcoin seja minerado apenas em $2140^{29}$.

O sistema atrai olhares e é crescente o ingresso de investidores, vendo que os pilares blockchain, rede $\mathrm{P} 2 \mathrm{P}$ e mineração sustentam o sucesso. Porém, bitcoin pode ser enquadrada como dinheiro ou apenas um

\footnotetext{
${ }^{27}$ BARBOSA, Tatiana Casseb B. M. et al. A Revolução das Moedas Digitais: Bitcoins e Altcoins. São Paulo: Revoar, 2016. p. 33.

${ }^{28}$ ULRICH, Fernando. Bitcoin: a moeda na era digital. São Paulo: Instituto Ludwig Von Mises Brasil, 2014. p. 38.

${ }^{29}$ SÁ, Victor. 80\% de todos os bitcoins já foram minerados. [S. 1.], 15 jan. 2018. Disponível em: https://portaldobitcoin.com/80-de-todos-os-bitcoins-ja-foram-minerados/. Acesso em: 19 jul. 2019.
} 
bem econômico? Para Fernando Ulrich, bens econômicos devem ser escassos e utilizados na ação humana ${ }^{30}$, logo, tendo em vista que o sistema bitcoin veda o gasto duplo (duas pessoas utilizando uma mesma unidade da criptomoeda) e o extenso comércio de moedas digitais, este assunto é pacificado. Já quanto a configurar como dinheiro, Graf destaca que para ser considerado como tal, ele deve ser um meio de troca universalmente aceito $^{31}$, pensamento o qual Fernando Ulrich compactua, sendo que seriam configuradas como "dinheiro mercadoria" ou "dinheiro commodity" 32 . Ou seja, desde que o bem seja amplamente difundido e comercializado como meio de troca, este é um dinheiro propriamente dito.

Porém, isso não confere a ele a característica de moeda. Pelo ordenamento jurídico somente o BACEN pode emitir moeda, sendo qualquer outro similar a isso não podendo ser enquadrado, como é o caso das criptomoedas. Entretanto, fugindo do estudo debruçado sobre os conceitos jurídicos e partindo para a perspectiva econômica, moedas digitais poderiam ser consideradas como moeda? Peter Šurda elenca liquidez, reserva de valor e custos de transação como influenciadores da escolha por uma moeda ${ }^{33}$. A primeira diz respeito à possibilidade de um ativo se tornar dinheiro (ou meio de troca), o que é uma problemática para as criptomoedas com o tempo solucionando, através da crescente ascensão de usuários ingressando à plataforma, contando com mais de 139 milhões de clientes da bitcoin client ${ }^{34}$.

A reserva de valor está relacionada à liquidez, integridade física e mudanças na oferta de dinheiro, o que, pela funcionamento digitalizado e resguardado pela blockchain, durabilidade permanente (enquanto a plataforma estiver no ar e a internet for viva no meio social) e as 21 milhões de moedas que inibem alterações drásticas na oferta de valor, combatendo, assim, a inflação que elas podem sofrer pela escassez relativa e oferta

\footnotetext{
${ }^{30}$ BARBOSA, Tatiana Casseb B. M. et al. A Revolução das Moedas Digitais: Bitcoins e Altcoins. São Paulo: Revoar, 2016. p. 88.

${ }^{31}$ GRAF, Konrad S. Bitcoins, the regression theorem, and that curious but unthreating empirical world. 27 fev. 2013. Disponível em: http://konradsgraf.com/blog1/2013/2/27/in-depth-bitcoins-theregression-theorem-and-that-curious-bu.html. Acesso em: 19 jul. 2019.

${ }^{32}$ ULRICH, Fernando. Bitcoin: a moeda na era digital. São Paulo: Instituto Ludwig Von Mises Brasil, 2014. p. 52.

${ }_{33}$ ŠURDA, Peter. Economics of bitcoin: is bitcoin na alternative to fiar currencies and gold? Diploma Thesis, Wirtschaftsuniversität Wien, 2012. Disponível em: http://dev.economicsofbitcoin.com/mastersthesis/mastersthesis-surda-2012-11-19b.pdf. Acesso em: 19 jul. 2019.

34 Usuários de criptomoedas crescem em 2018. [S. 1.], 13 dez. 2018. Disponível em: https://www.investimentosenoticias.com.br/bitcoins/usuarios-de-criptomoedas-crescem-em-2018. Acesso em: 19 jul. 2019.
} 
inelástica, vê-se que é um ponto positivo para as criptomoedas. E, por fim, os custos de transação, pela inexistência de um terceiro interventor nos negócios envolvendo bitcoins confere um reduzido custo comparado à atuação de entidades bancárias. Em suma, através da ótica de Šurda e lidando com o plano teórico, nota-se que, embora criptomoedas ainda tenha alguns desafios, podem ser economicamente tratadas como moeda.

Entretanto, o campo prático ainda demonstra algumas barreiras: riscos de mercado (pela indeterminação do valor), de sistema (temor pela segurança da plataforma), de "usabilidade" (perda de bitcoin pela ação humana direta do detentor da carteira de moedas ou de corretora) e risco econômico, elencadas por Ulrich ${ }^{35}$. Este autor destaca que, entre os riscos apresentados, o único não superado (ou superável pelo estudo e entendimento integral do funcionamento e da plataforma em si pelos que não conhecem a totalidade dele) é o de mercado, pela complexidade em determinar o comportamento da moeda dentro do mercado ${ }^{36}$. Entretanto, a volatilidade pode ser influenciada pelas exchanges (plataformas digitais para aquisição ou venda de criptomoedas), sendo que ela é inversamente proporcional ao volume de transações, sendo positiva a análise devido à crescente quantidade de bitcoins negociadas ${ }^{37}$.

Quanto ao risco econômico, vale o destaque de Fernando Ulrich:

Qual o lastro do ouro? A escassez inerente a suas propriedades físico-químicas. Qual o lastro do papel-moeda fiduciário? A confiança de que governos não inflacionarão a moeda, apoiada em leis de curso forçado que obrigam os cidadãos a aceitar a moeda como pagamento. Qual o lastro do Bitcoin? Propriedades matemáticas que garantem uma oferta monetária, cujo aumento ocorre a um ritmo decrescente a um limite máximo e pré sabido por todos os usuários da moeda. Após um bem ser empregado e reconhecido como moeda, seu lastro jaz na sua escassez relativa. Mas qual a distinção-chave entre o lastro do ouro e o do Bitcoin e o lastro das moedas estatais? O lastro físico é naturalmente provido de ou pretende assegurar uma escassez de oferta, assim como o lastro matemático do Bitcoin. O lastro governamental, porém, garante unicamente uma demanda mínima, mas não uma oferta inelástica. Em outras palavras, o lastro estatal não assegura uma

\footnotetext{
${ }^{35}$ ULRICH, Fernando. Entendendo os riscos e a segurança do bitcoin. [S. 1.], [20--?]. Disponível em: https://www.infomoney.com.br/blogs/cambio/moeda-na-era-digital/post/5647890/entendendo-osriscos-e-a-seguranca-do-bitcoin. Acesso em: 19 jul. 2019.

${ }^{36}$ Ibidem

${ }^{37}$ Ibid.
} 
moeda boa, apenas que até uma moeda ruim tenha vasta aceitação no mercado. ${ }^{38}$

Portanto, em teoria, operacional e estruturalmente a bitcoin se prostra como uma inovação atrativa aos olhos da modernidade. Entretanto, sua atuação prática recai sobre paradigmas e discussões não somente no campo econômico, como tratada, porém no jurídico, no qual apresenta desafios e uma análise detalhada para promover a discussão adequada quanto à temática.

\section{$5 \quad$ IMPACTOS JURÍDICOS DA BITCOIN}

A avaliação dos reflexos jurídicos é de suma importância pois, é pela compreensão da influência econômica, da postura de outros países e dos impactos no Brasil, que se permite a análise das medidas mais adequadas. Para tanto, em um primeiro momento, é necessário abrir uma discussão específica quanto à soberania nacional e, posteriormente, a movimentação do sistema jurídico brasileiro sobre o tema.

\subsection{A NOVA DINÂMICA SOBRE A SOBERANIA NACIONAL}

A soberania nacional não pode ser tratada como um assunto apartado, no qual o interesse do Estado, bem como seu poderio político e econômico deve ser analisado individualmente, sem integrá-lo a um contexto internacional. Isso se deve pela globalização, no qual os intercâmbios permeados pelo contexto histórico e político reduzem as barreiras internacionais em prol de um mundo mais interligado em todos os campos.

"É nesse sentido que a soberania deve ser confrontada com o Bitcoin. Falar em mitigação dessa em razão da impossibilidade de proibição da circulação da moeda digital, conforme será visto, somente seria possível se não apurada em consonância com os

${ }^{38}$ ULRICH, Fernando. Bitcoin: a moeda na era digital. São Paulo: Instituto Ludwig Von Mises Brasil, 2014. p. 64. 
conceitos modernos de globalização e internacionalização das relações humanas."39

Portanto, as tratativas quanto a esse princípio econômico não é confrontar integralmente com a finalidade de extingui-la, mas sim mitigada de acordo com as relações entre países permeadas pela globalização. A harmonia entre a um conceito historicamente enraizado na sociedade que confere ao Estado sua característica de soberano para decisões que atendam a persecução do bem comum e o contexto de uma população mundial (globalizada) é necessária para que seja permissiva a inserção das moedas digitais sem gerar um conflito ou uma disputa.

\subsection{NATUREZA JURÍDICA E A REGULAMENTAÇÃO BRASILEIRA}

Analisando as criptomoedas de acordo com a ótica da legislação brasileira atual, há que se discutir a sua natureza jurídica e como ela se enquadra no ordenamento jurídico. A princípio sabe que elas não são moedas propriamente ditas pela $n^{\circ} 4.595 / 64$ anteriormente destacada, tampouco são consideradas moedas digitais, assunto esclarecido pelo próprio Banco Central do Brasil através do comunicado $n^{\circ} 31.379 / 17$ :

A denominada moeda virtual não se confunde com a definição de moeda eletrônica de que trata a Lei $\mathrm{n}^{\circ} \mathbf{1 2 . 8 6 5}$, de 9 de outubro de 2013, e sua regulamentação por meio de atos normativos editados pelo Banco Central do Brasil, conforme diretrizes do Conselho Monetário Nacional. Nos termos da definição constante nesse arcabouço regulatório consideram-se moeda eletrônica 'os recursos em reais armazenados em dispositivo ou sistema eletrônico que permitem ao usuário final efetuar transação de pagamento'. Moeda eletrônica, portanto, é um modo de expressão de créditos denominados em reais. Por sua vez, as chamadas moedas virtuais não são referenciadas em reais ou em outras moedas estabelecidas por governos soberanos ${ }^{40}$

Poderiam, então, ser tratadas como títulos de crédito? O estudo principiológico acerca do tema demonstra o difícil enquadramento das

\footnotetext{
${ }^{39}$ TEIXEIRA, R. V. G.; SILVA, F. R. Bitcoin e a (im)possibilidade de sua proibição: uma violação à soberania do Estado?. Revista brasileira de políticas públicas, [S. 1.], 2017. Revista eletrônica.

${ }^{40}$ BANCO CENTRAL DO BRASIL. COMUNICADO no 31.379. Brasília, 2017. Disponível em: http://www.bcb.gov.br/pre/normativos/busca/normativo.asp?numero=31379\&tipo=Comunicado\&dat $\underline{a=16 / 11 / 2017}$. Acesso em: 19 jul. 2019.
} 
criptomoedas dentro desta categoria, por confrontarem o princípio da cartularidade (o exercício do direito sobre a cártula é intrínseco, sendo opcional para as moedas digitais), por não possuir valor contido em um título específico (princípio da literalidade), mas sim sujeito ao valor do mercado que elas representam no momento da transação e, por não seguirem o princípio da autonomia pela desmaterialização da obrigação sobre um documento.

As criptomoedas poderiam ser enquadradas, ao menos, como bens? Doutrinariamente sendo "bem" algo dotado de interesse jurídico e/ou econômico, para Tartuce ${ }^{41}$, a aplicação do Código Civil poderia alcançar as moedas digitais, nos contratos de compra e venda, de permuta e doação, por exemplo. Podem ser consideradas como bens pois a Receita Federal através da Consulta Pública RB n 06/2018 indicou que a tributação de criptoativos deveria ser feita através da categoria "outros bens" 42 .

Entretanto, através da análise jurídica, nota-se a escassez de uma regulamentação de criptomoedas no cenário brasileiro atual. Porém, é necessário legislar sobre moedas digitais? E se a resposta é afirmativa, esta tarefa é designada a cada Estado em seus limites políticos ou seria algo a ser perseguido conjuntamente entre os países do mundo?

$\mathrm{O}$ primeiro questionamento gera o confronto entre o pensamento liberal e o intervencionismo econômico. Para Julian Assange, defensor da não intervenção, a inovação, a plataforma e o funcionamento que opera sem um servidor central é atraente demais para um controle repressor ${ }^{43}$. O pensamento de Assange é perigoso quando a subjetividade dos usuários que se utilizam da rede é levada em conta, isso porque a confiança dos que transacionam na plataforma não deve ser tratada como perfeita, pois prejudica a confiabilidade quando pode ser comercializado, por exemplo, produtos ilícitos nela, ou até seja meio para lavagem de dinheiro. Ponderar por uma autoridade que interfira nas transações mas que consolide e fortaleça o sistema e a própria moeda é totalmente viável, pois a persecução para dirimir condutas delituosas é o que mais conferiria aos novos usuários para ingressarem no universo das criptomoedas.

\footnotetext{
${ }^{41}$ TARTUCE, Flávio. Direito Civil 1: Lei de Introdução e Parte Geral. 10 a ed. Rio de Janeiro: Forense; São Paulo: Método.. 2014. p. 215.

42 RECEITA FEDERAL. CONSUlta PÚBliCA RFB No 06/2018. Brasília, 30 out. 2018. Disponível em: http://receita.economia.gov.br/sobre/consultas-publicas-e-editoriais/consultapublica/arquivos-e-imagens/consulta-publica-rfb-no-06-2018.pdf. Acesso em: 19 jul. 2019.

${ }^{43}$ ASSANGE, Julian. Cypherpunks: liberdade e o futuro da internet. São Paulo: Boitempo, 2013. p. 90.
} 
Esclarecendo, então, por uma legislação garantidora de direitos e preventiva, esta deveria ser operada por quem e de qual forma? Tendo em vista as recentes tentativas de regulamentação brasileira através do Projeto de Lei $\mathrm{n}^{\mathrm{o}} 2.303 / 15^{44}$ que claramente apresentava erros conceituais e com o texto de lei demonstrando aversão às moedas digitais, posicionamento contrário ao extremo da maioria dos países, principalmente os que estão no $\mathrm{G} 20^{45}$, além da dimensão global que estes criptoativos vão criando, conclui-se que o melhor caminho seja a tratativa uníssona entre os países.

Para tanto, Tatiana Casseb B. M. Barbosa sugere a criação de um órgão internacional chamado de "Organização Internacional sobre Moedas Digitais" (OIMD), com a função de normatizar de forma preventiva e repressiva, além de promover informativos acerca do tema, bem como delimitar as tratativas através de diretrizes e parâmetros e instituir um cadastro capaz de atrelar os usuários da plataforma aos respectivos indivíduos detentores das carteiras ${ }^{46}$. A proposta da autora exigiria 2 representantes de cada país membro para realizar as divulgações sobre a moeda através de cartilhas e vídeos, desenvolver meios para validação de recibos emitidos e para sanar as dúvidas de consumidores, fiscalizar reclamações e acusações, e estudar os avanços e efeitos gerados pelos sistemas das criptomoedas ${ }^{47}$. Para otimização da proposta, bem como para garantir que os países membros sigam o convencionado pela OIMD, seria interessante a criação de órgãos para atuação interna em cada país, sendo que os 2 representantes da organização mundial citada seriam os "chefes" da entidade nacional criada para estes fins, o que seria harmonicamente positivo para os Estados que permitissem mitigar sua soberania para prevalecer os anseios mundiais.

Em suma, a constante disseminação das criptomoedas no cenário mundial necessita superar paradigmas e temores provindos da falta de conhecimento juntamente com o aprimoramento do sistema a ponto de conferir a confiabilidade e operabilidade que todos desejam, isso devendo

\footnotetext{
${ }^{44}$ BRASIL. PROJETO DE LEI N ${ }^{\circ}$ 2.303, DE 08 DE JULHO DE 2015. Dispõe sobre a inclusão das moedas virtuais e programas de milhagem aéreas na definição de "arranjos de pagamento" sob a supervisão do Banco

Central. Brasília, 2015. Disponível em:

http://www.camara.gov.br/proposicoesWeb/fichadetramitacao?idProposicao=1555470. 2018.

${ }^{45}$ GUSSON, Cássio. G20: conheça o status do Bitcoin em cada país integrante do grupo. [S. 1.], 17 mar. 2018. Disponível em: https://www.criptofacil.com/g20-conheca-o-status-do-bitcoin-em-cadapais-integrante-do-grupo/. Acesso em: 19 jul. 2019.

${ }^{46}$ BARBOSA, Tatiana Casseb B. M. et al. A Revolução das Moedas Digitais: Bitcoins e Altcoins. São Paulo: Revoar, 2016. p. 315.

${ }^{47}$ Ibidem
} 
ser feito através de um órgão internacional capaz de solucionar essa problemática, bem como pacificar a questão a nível global, tratando de forma uniforme um assunto que atinge a todos os países, direta ou indiretamente. "Salienta-se que uma normatização dará um sentido de legitimidade que deve ajudar a reduzir a insegurança que tem mantido os comerciantes e investidores fora da ação" 48 , estas medidas devem ser o ponto de partida para que a sociedade mundial aprimore sua forma de lidar sobre um assunto que já criou raízes e não há mais perspectiva de abolição. Sendo assim, pavimentar a jornada irreversível e a busca por otimizar o uso e compreensão das criptomoedas é o caminho menos danoso e mais frutífero.

\section{CONSIDERAÇÕES FINAIS}

Criptomoedas são decorrência do contexto histórico-social que envolve a absorção de conceitos pertinentes da evolução monetária (em específico a moeda fiduciária, escritural e o crédito) e ascensão do mundo globalizado, este possuindo pilares fundantes das moedas digitais: a internet com seu ciberespaço, o sistema financeiro atual e os intercâmbios internacionais. Sistematicamente, conferir a um software o poder de movimentar e difundir uma nova moeda foi o suficiente para atrair olhares de investidores, estes confiando que o futuro está sim na força computacional.

Entretanto, as moedas digitais devem ser tratadas com cautela, pois no plano prático ela necessita suprir incertezas e dirimir impactos para que possa impactar da forma mais positiva. Para tanto, a análise constitucional, em primeiro plano, é o ponto inicial da discussão, verificando a permissividade que a Constituição Econômica Brasileira se abre para a ascensão dos criptoativos. A soberania nacional como princípio econômico deve ser tratada com mais cautela, visto que não é impossível desassociar um conceito enraizado por séculos (ou até extingui-lo) para a introdução de novos pensamentos que podem comprometer a segurança que o Estado confere nos diversos campos de atuação. O sistema financeiro nacional reforça que a atuação direta do Estado na atividade econômica deve ocorrer, principalmente buscando alcançar as finalidades em prol do bem comum, respeitando os princípios e fundamentos da Constituição

${ }^{48}$ Ibid., p. 321. 
Econômica, a inserção de criptomoedas no mercado nacional não interfere essa persecução, tampouco inibe a atuação estatal.

Além disso, há riscos que devem ser vencidos (dentre alguns já superados), sendo o maior dele a respeito do plano jurídico. A regulamentação é a via que deve ser pavimentada, porém sob a ótica internacional, em decorrência do impacto a nível mundial que as criptomoedas causaram. Com isso, o caminho seria a criação de um órgão internacional que exigiria a adesão dos países membros para tratar de forma uníssona todas as incertezas na busca por pacificar a situação e permitir que a sociedade prospere diante das inovações que o mundo moderno e globalizado exige (e que se torna impossível dar passos para trás).

O fato é que, já são 14 mil lojas transacionando em criptomoedas no mundo de acordo com o coinmap ${ }^{49}$, movimentando 8,3 bilhões de reais no Brasil somente em $2018^{50}$. Os impactos jurídicos devem ser lidados com a devida dimensão que os econômicos requisitam, qualquer medida negativa às inovações tecnológicas e cibernéticas é um caminho impossível de ser percorrido, a modernidade, diante da globalização e dos constantes avanços, faz um convite que não pode mais ser recusado.

\section{REFERÊNCIAS BIBLIOGRÁFICAS}

AGUIAR, B. A. T. A constituição econômica: breve síntese. [S. l.], 2013. Disponível em: https://ambitojuridico.com.br/edicoes/revista-110/a-constituicao-economica-breve-sintese/. Acesso em: 18 jul. 2019.

ASSANGE, Julian. Cypherpunks: liberdade e o futuro da internet. São Paulo: Boitempo, 2013.

BAGNOLI, Vicente. Direito econômico. São Paulo: Atlas, 2008.

BANCO CENTRAL DO BRASIL. Como funciona o sistema financeiro nacional. [S. 1.], abr. 2008. Disponível em:

https://www.bcb.gov.br/Pre/bcUniversidade/Palestras/Sistema\%20Financeiro\%20Nacional.pdf. Acesso em: 19 jul. 2019.

\footnotetext{
${ }^{49}$ Coinmap. 2018. Disponível em: https://coinmap.org/\#/. Acesso em: 12 dez. 2018.

50 RECEITA FEDERAL. CONSULTA PÚBLICA RFB No 06/2018. Brasília, 30 out. 2018. Disponível em: http://receita.economia.gov.br/sobre/consultas-publicas-e-editoriais/consultapublica/arquivos-e-imagens/consulta-publica-rfb-no-06-2018.pdf. Acesso em: 19 jul. 2019.
} 
BANCO CENTRAL DO BRASIL. COMUNICADO no 31.379. Brasília, 2017. Disponível em: https://www.bcb.gov.br/estabilidadefinanceira/exibenormativo?tipo=Comunicado\&numero $=31379$. Acesso em: 18 jul. 2019.

BANCO CENTRAL DO BRASIL. História do BC. [S. 1.], [20--?]. Disponível em: https://www.bcb.gov.br/pre/historia/historiabc/historia_bc.asp?frame=1. Acesso em: 19 jul. 2019.

BANCO CENTRAL DO BRASIL. Origem e evolução do dinheiro. [S. 1.], [20--?]. Disponível em: https://www.bcb.gov.br/htms/origevol.asp. Acesso em: 18 jul. 2019.

BARBOSA, Tatiana Casseb B. M. et al. A Revolução das Moedas Digitais: Bitcoins e Altcoins. São Paulo: Revoar, 2016.

BATISTI, N. E. M. Evolução da ordem econômica no contexto político-econômico das constituições brasileiras. 2007. Dissertação (Mestrado em Direito Negocial) - Universidade Estadual de Londrina, Londrina, 2007. Disponível em:

http://www.dominiopublico.gov.br/download/teste/arqs/cp044787.pdf. Acesso em: 19 jul.

Bitcoin e o impacto da tecnologia blockchain na economia mundial. [S. 1.], 23 jul. 2018. Disponível em: https://www.hsm.com.br/bitcoin-e-o-impacto-da-tecnologia-blockchain-naeconomia-mundial/. Acesso em: 19 jul. 2019.

Bitcoin e o impacto da tecnologia blockchain na economia mundial. [S. 1.], 23 jul. 2018. Disponível em: https://www.hsm.com.br/bitcoin-e-o-impacto-da-tecnologia-blockchain-naeconomia-mundial/. Acesso em: 19 jul. 2019.

BRASIL. [Constituição (1988)]. CONSTITUIÇÃO DA REPÚBLICA FEDERATIVA DO BRASIL. Organização de Alexandre de Moraes. 16.ed. São Paulo: Atlas, 2000.

BRASIL. PROJETO DE LEI No 2.303, DE 08 DE JULHO DE 2015. Dispõe sobre a inclusão das moedas virtuais e programas de milhagem aéreas na definição de "arranjos de pagamento" sob a supervisão do Banco

Central. Brasília, 2015. Disponível em:

http://www.camara.gov.br/proposicoesWeb/fichadetramitacao?idPr oposicao $=1555470.2018$.

Coinmap. 2018. Disponível em: https://coinmap.org/\#/. Acesso em: 12 dez. 2018.

GONÇALVES, Reinaldo. Globalização econômica. Disponível em:

http://www.ie.ufrj.br/intranet/ie/userintranet/hpp/arquivos/texto_no._1_globalizacao_economica.pdf. Acesso em: $10 \mathrm{dez} .2018$.

GRAF, Konrad S. Bitcoins, the regression theorem, and that curious but unthreating empirical world. 27 fev. 2013. Disponível em:

http://konradsgraf.com/blog1/2013/2/27/in-depth-bitcoins-theregression-theorem-and-that-curious-bu.html. Acesso em: 19 jul. 2019. 
GUSSON, Cássio. G20: conheça o status do Bitcoin em cada país integrante do grupo. [S. 1.], 17 mar. 2018. Disponível em: https://www.criptofacil.com/g20-conheca-o-status-do-bitcoin-em-cadapais-integrante-do-grupo/. Acesso em: 19 jul. 2019.

HAYEK, Friederich A. Desestatização do dinheiro. São Paulo: Instituto Ludwig von Mises, 2011.

MOREIRA, Vital. Economia e Constituição, 1979 apud FONSECA, João Bosco Leopoldino. Direito Econômico. $2^{\text {a }}$ Edição, Rio de Janeiro: Editora Forense, 1997.

RECEITA FEDERAL. CONSULTA PÚBLICA RFB Nº 06/2018. Brasília, 30 out. 2018. Disponível em: http://receita.economia.gov.br/sobre/consultas-publicas-e-editoriais/consultapublica/arquivos-e-imagens/consulta-publica-rfb-no-06-2018.pdf. Acesso em: 19 jul. 2019.

ROQUETTE, Luis. Bitcoin e regulamentação pelo mundo: Uma análise completa sobre o futuro da moeda. [S. 1.], 24 dez. 2018. Disponível em: https://www.oinvestidormoderno.com.br/bitcoin-eregulamentacao-uma-analise-completa/. Acesso em: 19 ago. 2019.

ROQUETTE, Luis. Bitcoin e regulamentação pelo mundo: Uma análise completa sobre o futuro da moeda. [S. 1.], 24 dez. 2018. Disponível em: https://www.oinvestidormoderno.com.br/bitcoin-eregulamentacao-uma-analise-completa/. Acesso em: 19 ago. 2019.

SÁ, Victor. 80\% de todos os bitcoins já foram minerados. [S. 1.], 15 jan. 2018. Disponível em: https://portaldobitcoin.com/80-de-todos-os-bitcoins-ja-foram-minerados/. Acesso em: 19 jul. 2019.

SILVA, Vinicius Carlos da. História da moeda. [S. 1.], [20--?]. Disponível em: https://www.portalsaofrancisco.com.br/historia-geral/historia-da-moeda. Acesso em: 15 jan. 2019.

Singer, Paul - 1032. Aprender economia / Paul Singer. $21^{\circ}$ ed.- São Paulo. Rossetti, José Paschoal, Introdução à economia / São Paulo: Atlas, 1994.

ŠURDA, Peter. Economics of bitcoin: is bitcoin na alternative to fiar currencies and gold? Diploma Thesis, Wirtschaftsuniversität Wien, 2012. Disponível em:

http://dev.economicsofbitcoin.com/mastersthesis/mastersthesissurda-2012-11-19b.pdf. Acesso em: 19 jul. 2019.

TARTUCE, Flávio. Direito Civil 1: Lei de Introdução e Parte Geral. 10ª ed. Rio de Janeiro: Forense; São Paulo: Método. 2014.

TAVARES, André Ramos. Direito Constitucional Econômico. São Paulo: Método, 2011.

TEIXEIRA, R. V. G.; SILVA, F. R. Bitcoin e a (im)possibilidade de sua proibição: uma violação à soberania do Estado?. Revista brasileira de políticas públicas, [S. 1.], 2017. Revista eletrônica.

ULRICH, Fernando. Bitcoin: a moeda na era digital. São Paulo: Instituto Ludwig Von Mises Brasil, 2014.

ULRICH, Fernando. Entendendo os riscos e a segurança do bitcoin. [S. 1.], [20--?]. Disponível em: https://www.infomoney.com.br/blogs/cambio/moeda-na-era-digital/post/5647890/entendendo-osriscos-e-a-seguranca-do-bitcoin. Acesso em: 19 jul. 2019. 
Usuários de criptomoedas crescem em 2018. [S. 1.], 13 dez. 2018. Disponível em:

https://www.investimentosenoticias.com.br/bitcoins/usuarios-de-criptomoedas-crescem-em-2018. Acesso em: 19 jul. 2019.

VIEIRA, J. A. G.; PEREIRA, H. F. S.; PEREIRA, W. N. A. Histórico do Sistema Financeiro Nacional. E-locução - Revista científica da FAEX, Extrema - MG, 2012. Disponível em:

https://faex.edu.br/_arquivos/_revistas/322125001348776758_10.pdf. Acesso em: 19 jul. 2019. 